\title{
Correction to: Effects of short- and long- term glucocorticoid-induced osteoporosis on plasma metabolome and lipidome of ovariectomized sheep
}

Diana Cabrera ${ }^{1 *}$, Marlena Kruger ${ }^{2,3}$, Frances M. Wolber ${ }^{3,4,5}$, Nicole C. Roy ${ }^{1,3,6}$ and Karl Fraser ${ }^{1,3,6}$

\section{Correction to: BMC Musculoskelet Disord (2020) 21:349 https://doi.org/10.1186/s12891-020-03362-7}

Following publication of the original article [1], the authors noticed that incorrect Fig. 4 was published.

The Fig. 4 is a heatmap showing the longitudinal response for each lipid in the short-term approach; however the short term approach involves only the control group, OVX group and OVXG and three time points ( 0,1 and 2 months).

The correct Fig. 4 is shown below.

\begin{abstract}
Author details
${ }^{1}$ Food Nutrition \& Health Team, AgResearch Grasslands, Tennent Drive, Palmerston North 4442, New Zealand. ${ }^{2}$ School of Health Sciences, Massey University, Tennent Drive, Palmerston North 4442, New Zealand. ${ }^{3}$ Riddet Institute, Massey University, Palmerston North 4442, New Zealand. ${ }^{4}$ School of Food Advanced technology, Massey University, Tennent Drive, Palmerston North 4442, New Zealand. ${ }^{5}$ Centre for Metabolic Health Research, Massey University, Tennent Drive, Palmerston North 4442, New Zealand. ${ }^{6}$ High-Value Nutrition National Science Challenge, Auckland 1142, New Zealand.
\end{abstract}

Published online: 29 July 2020

\section{Reference}

1. Cabrera D, Kruger M, Wolber FM, et al. Effects of short- and long-term glucocorticoid-induced osteoporosis on plasma metabolome and lipidome of ovariectomized sheep. BMC Musculoskelet Disord. 2020;21:349. https:// doi.org/10.1186/s12891-020-03362-7.

The original article can be found online at https://doi.org/10.1186/s12891020-03362-7.

* Correspondence: diana.cabrera@agresearch.co.nz

${ }^{1}$ Food Nutrition \& Health Team, AgResearch Grasslands, Tennent Drive, Palmerston North 4442, New Zealand

Full list of author information is available at the end of the article

(c) The Author(s). 2020 Open Access This article is licensed under a Creative Commons Attribution 4.0 International License, which permits use, sharing, adaptation, distribution and reproduction in any medium or format, as long as you give appropriate credit to the original author(s) and the source, provide a link to the Creative Commons licence, and indicate if changes were made. The images or other third party material in this article are included in the article's Creative Commons licence, unless indicated otherwise in a credit line to the material. If material is not included in the article's Creative Commons licence and your intended use is not permitted by statutory regulation or exceeds the permitted use, you will need to obtain permission directly from the copyright holder. To view a copy of this licence, visit http://creativecommons.org/licenses/by/4.0/. The Creative Commons Public Domain Dedication waiver (http://creativecommons.org/publicdomain/zero/1.0/) applies to the data made available in this article, unless otherwise stated in a credit line to the data. 


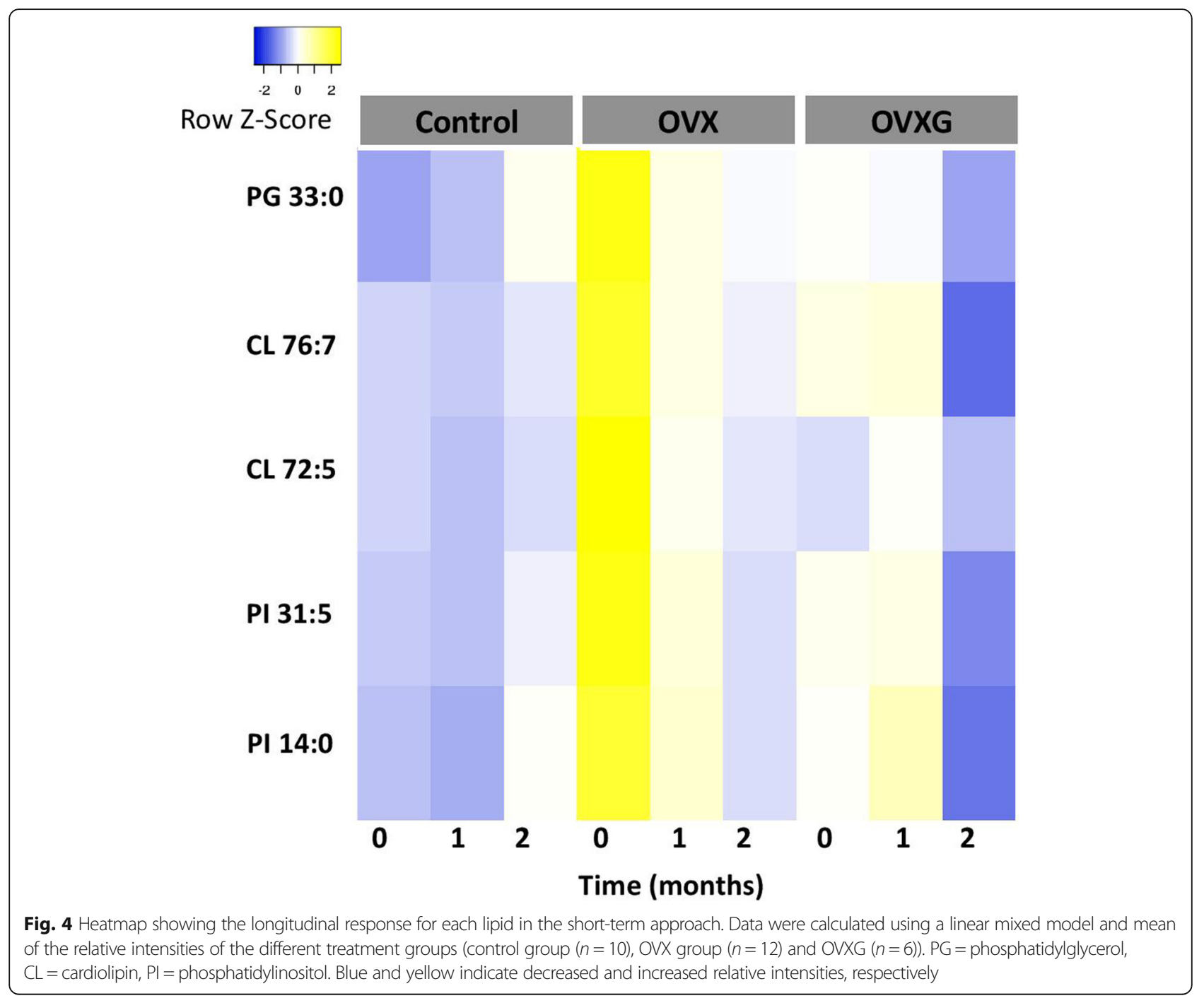

